\title{
Project ECHO Integrated Within the Oregon Rural Practice-based Research Network (ORPRN)
}

\author{
Margaret McLain McDonnell, MPH, Nancy C. Elder, MD, MSPH, Ron Stock, MD, MA, \\ Miriam Wolf, BS, Anna Steeves-Reece, MPH, and Tuesday Graham, BS
}

Two key advancements in improving the quality of primary care have been practice-based research networks (PBRNs) and Project Extension for Community Health care Outcomes (ECHO). PBRNs advance quality through research and transformation projects, often using practice facilitation. Project ECHO uses case-based telementoring to support community clinicians to deliver best-practice care. Although some PBRNs sponsor ECHO programs, the Oregon Rural Practice-based Research Network (ORPRN) has created a statewide network for ECHO programs (Oregon ECHO Network [OEN]). We facilitated a unique funding stream for the OEN by partnering with payers and health systems. The purpose of this article is to share our experience of how OEN programs and ORPRN research and transformation projects enhance practice recruitment and retention and improve financial stability. We describe the synergy between ORPRN projects and ECHO programs using 3 examples: tobacco cessation, chronic pain and opioid prescribing, and diabetes management. We highlight challenges and opportunities in these examples, beginning with their development, their implementation, and their ultimate alignment, despite varied funding streams and timelines. We believe that incorporating the OEN within ORPRN has been a success for both PBRN research and Project ECHO programs, allowing us to better support primary care practices across the state. (J Am Board Fam Med 2020;33:789-795.)

Keywords: Clinical Practice Patterns, Community-Based Participatory Research, Community Health Services, Continuing Medical Education, Disease Management, Distance Education, Oregon, Practice-Based Research, Primary Health Care, Quality Improvement, Telemedicine

\section{Introduction}

The history of primary care practice-based research networks (PBRNs) dates back to the 1970s, with steady growth since then. ${ }^{1}$ A collection of practices that affiliate to conduct research focused on delivering care to the patients they serve, PBRNs are usually affiliated with academic health centers. ${ }^{2}$ Over the decades, the research performed by PBRNs has grown and matured. Early research was highly descriptive, illuminating the practice of primary care, ${ }^{1-5}$

This article was externally peer reviewed.

Submitted 30 January 2020; revised 12 May 2020; accepted 19 May 2020.

From Oregon Rural Practice-based Research Network at Oregon Health \& Science, University, Portland (MMM, NCE, RS, MW, AS-R, TG).

Funding: None.

Conflict of Interest: None.

Corresponding author: Margaret McLain McDonnell, MPH, Director, Oregon ECHO Network, Oregon Rural Practice-based Research Network, 3181 SW Sam Jackson Park Rd, L222, Portland, OR 97239 (E-mail: mclainma@ ohsu.edu). whereas current PBRN research also encompasses practice transformation and quality improvement support, community-based participatory research, dissemination, implementation, and pragmatic clinical trials. ${ }^{1,4,6-11}$ Estimates suggest that annual infrastructure requirements for running a PBRN range from $\$ 69 \mathrm{~K}$ for basic networks to $\$ 300 \mathrm{~K}$ for more complex networks. ${ }^{12}$

In recent years, PBRNs have faced new challenges. Infrastructure funding from the Agency for Health care Research and Quality and others that supported early PBRNS is no longer available. Primary care practice has changed, as clinicians moved from independent practices to employment in health systems. There are also a growing number of research and improvement opportunities sponsored by payors, health systems, and other quality improvement programs beyond PBRNs, for example, the Comprehensive Primary Care plus program from the Centers for Medicare and Medicaid Innovation Center. These changes have collectively 
increased the challenges PBRNs face to secure funding and recruit practices. ${ }^{1,4,13,14}$

A primary care practice improvement innovation in recent years has been Project Extension for Community Health care Outcomes (ECHO). ${ }^{15,16}$ The ECHO model was developed at the University of New Mexico in 2003 as a platform for teaching community providers to deliver best-practice medical services to underserved populations with chronic, complex conditions by using case-based telementoring programs. ${ }^{15}$ Project ECHO uses a "hub" and "spoke" model to promote knowledge exchange between health care specialists typically located at academic centers (the hub) and primary care providers at the front line of community health care (the spokes). ${ }^{17}$ In the past decade, ECHO programs, generally affiliated with academic health centers, health systems, and governments have spread across the globe. ${ }^{18}$ Several key goals of ECHO programs align with those of primary care PBRNS, including supporting primary care quality, assisting practice transformation, and working within existing practice workflows. Little is known, however, about the process by which ECHO programs can emerge within or interact with existing PBRN structures.

This article seeks to describe the structure of building an ECHO Network within a PBRN and to delineate the benefits and challenges of the relationship to both ECHO and practice-based research. This work is located within the Oregon Rural Practice-based Research Network (ORPRN), a statewide PBRN affiliated with Oregon Health \& Sciences University (OHSU). ${ }^{3}$

\section{Creation of Oregon ECHO Network}

Founded in 2002, ORPRN has followed the trajectory of other successful PBRNs, growing from 6 practices to over 300, completing over 85 funded research and transformation projects, and developing a strength in practice facilitation. ${ }^{19,20}$ In 2017, ORPRN created the Oregon ECHO Network (OEN), an infrastructure for statewide ECHO programs. The genesis for the $\mathrm{OEN}$ is related to the structure of Oregon's Medicaid Coordinated Care Organizations (CCO), an accountable care organization type of model. In 2012, Oregon established an agreement with Centers for Medicare \& Medicaid Services to create 16 CCOs that provided Medicaid managed care coverage to all regions in the state. Centers for Medicare \& Medicaid Services provided a $\$ 1.9$ billion investment over 5 years to create the CCOs in exchange for the state of Oregon agreeing to limit per-capita Medicaid spending growth. ${ }^{19}$ Significant changes to health care delivery were necessary to meet this goal, including establishing quality incentive metrics to assess the quality of care delivery. ${ }^{20}$ The Oregon Health Authority (OHA) Transformation Center, a center dedicated to innovation and quality improvement to support Oregon's health care goals, saw Project ECHO as a promising model to support these transformation efforts. The $\mathrm{OHA}$ initiated a literature review, a qualitative scan of state clinicians to determine current ECHO participation, education interest and needs, a specifications analysis, and recommendations for a statewide approach to Project ECHO programming.

In 2016, the OHA Transformation Center selected ORPRN to complete a needs assessment regarding the benefit of a statewide infrastructure for Project ECHO. ORPRN was selected based on its established relationships with primary care practices and communities. The assessment included a more comprehensive statewide scan of clinician interest in ECHO programs, informal interviews with a selection of academic medical centers offering ECHO programs, creation of an ECHO advisory board, and a final report. The advisory board was comprised of health care leaders from large health systems, CCOs, commercial payers, and medical associations.

At the conclusion of the assessment, ORPRN leadership felt that ORPRN itself was well suited to create and support the OEN. In fall 2017, 5 of the original organizations that participated in the ECHO advisory board (4 CCOs and 1 health system) agreed to financially support the Oregon ECHO Network, housed within ORPRN, with yearly "membership" fees and became the OEN Advisory Board. In the following years, more partners committed to ongoing financial support of OEN. Supporting organizations help select the topics of a minimum of $2 \mathrm{ECHO}$ programs each year and clinicians affiliated with these partners have priority to participate in the programs. In the following 3 years, synergy between practice-based research and ECHO programs grew, enhancing both recruitment and specific project development.

\section{Recruitment Synergy}

Recruitment can be an issue for both PBRN research and ECHO participation. ${ }^{1,17,21}$ In the past 
Table 1. Primary Care Practice Participation in Oregon Rural Practice-based Research Network Projects and Extension for Community Healthcare Outcomes Programs (2014-2020)

\begin{tabular}{lc}
\hline Type of Participation & $\begin{array}{c}\text { Number of } \\
\text { Practices }\end{array}$ \\
\hline Research or improvement projects & 345 \\
ECHO programs (primary care only) & 225 \\
Both research or improvement projects and & 104 \\
ECHO programs & 241 \\
Only research or improvement projects & 121 \\
Only ECHO programs (primary care only) & \\
\hline
\end{tabular}

ECHO, Extension for Community Healthcare Outcomes.

5 years, ORPRN has recruited over 350 unique practices for a number of research and quality improvement projects. We have used various methods for this recruitment, beginning with previous or existing personal relationships and warm handoffs from colleagues and then progressing to emails, newsletters, and phone calls. More physicians are now employed by larger health systems, often requiring multiple levels of communication when recruiting them for projects. ${ }^{1}$ OEN recruits through e-mails and newsletters, and OEN Advisory Board partners (CCOs and health systems) publicize and encourage participation from their own member clinicians. Although there is overlap in clinicians and practices who have worked with ORPRN on a research or improvement project and participated in at least 1 OEN program, there are also clinicians who have only been active in either research or ECHO, as summarized in Table 1.

Databases maintained by ORPRN and OEN of clinicians and practices allow not only identification of clinicians who might be interested in new opportunities but also warm handoffs and introductions by ORPRN and OEN staff, including project managers, investigators, and practice facilitators (PFs). Primary care practices, however, regularly have turnover and changes in key practice staff, including physicians, other clinicians, medical directors, and office managers. The more connections that ORPRN has with a practice, including participation in an ECHO program, the easier it is to keep this information up to date. A challenge we face is assuring that our communications with practice clinicians and staff make clear that OEN is a part of
ORPRN. With clear and consistent communication, we maximize the benefit of relationship building.

\section{Project Synergy}

As OEN and ORPRN have matured, we have found ways to inform and create projects using the traditional strengths of PBRNs (practice facilitation, implementation, transformation and research expertise, and physician/practice advisory board input) and OEN's new assets (specialty clinical expertise, CCO and health system advisory board input, and regular surveys of physicians' clinical needs). We describe these synergies in 3 examples below.

\section{Reducing Tobacco Prevalence}

Reducing Tobacco Prevalence is an example of a project in which the ECHO program and practice technical assistance were created together but performed independently. In 2018, ORPRN received funding from the OHA Transformation Center to address tobacco use in the Medicaid population, as tobacco use prevalence and tobacco cessation were 2 of Oregon's 2018 CCO quality incentive metrics. We designed the project based on our experiences working with over 100 primary care practices on quality improvement activities for cardiovascular health, including tobacco cessation. ${ }^{22}$ ORPRN's goals for the tobacco project included increasing the capacity of rural primary care practices to routinely screen for, document, and counsel patients about tobacco use. After conducting a needs assessment, ORPRN created a project that began with a 5 -session ECHO program for clinical and CCO quality improvement staff. Didactic presentation topics included office-based systems for screening, cessation counseling, pharmaceutical interventions, referral to community services, and working with special populations. Physicians and other participants, including quality improvement and nursing staff, then presented their own cases for discussion. Participants in the ECHO program benefited from the normalization that occurs through shared experiences. Following the ECHO program, PFs from ORPRN provided targeted technical assistance around tobacco cessation to 6 primary care practices ( 5 of which had staff who also participated in the ECHO program). As part of a qualitative assessment of the project, practice facilitators noted that 
practices that had participated in ECHO were primed with ideas for quality improvement at the initial facilitation session-something that had been unusual in previous projects with no prior $\mathrm{ECHO}$ program. At the conclusion of the project, each of the 6 practices successfully implemented processes that improved tobacco screening and/or cessation counseling.

\section{Chronic Pain and Opioid Prescribing}

Improving chronic pain and opioid prescribing is an example of a project in which the ECHO program and practice technical assistance were created separately, with an established ECHO program informing a new implementation project. In 2017, the Addiction Medicine section of the OHSU Department of Internal Medicine collaborated with OEN to implement ECHO programs related to substance use disorders. In this ongoing relationship, the addiction specialists develop and implement the curriculum while OEN recruits participants, provides information technology support, completes project evaluations, and submits the continuing education accreditation. Since their inception, these popular addiction ECHO programs have engaged over 600 clinicians and other health professionals. The ECHO program topics have evolved over time based on participant feedback, including the addition of a Chronic Pain and Opioids ECHO program, which was created after participants requested more support to address chronic pain in the primary care setting.

In 2019, as part of a large statewide initiative to decrease opioid overdoses, the OHA approached ORPRN to submit a proposal to provide assistance to primary care practices to improve chronic pain care and opioid prescribing. The project Improving Pain and Opioid Management in Primary Care (PINPOINT) was funded and is now recruiting practices. It builds on ORPRN's experience tailoring facilitation support for individual practices and other regional chronic pain management programs. ${ }^{23-25}$ Due to its focus on pain and opioid prescribing, PINPOINT is not able to fully support additional concepts, such as office-based medication-assisted treatment, via practice facilitation. However, by incorporating the existing addiction ECHO programs into the assistance given to practices, we have the opportunity to offer this additional training and support to participants. A key outcome of this work will be to establish if ongoing
ECHO program participation will sustain improvements made during the facilitated components of the project.

\section{Diabetes Management}

Two new projects in development now are related to improving the primary care of patients with type 2 diabetes. Although the 2 projects, an ECHO program and technical assistance to practices, have different funding, as both are in the planning phase at the same time, we are able to create the projects to complement and support each other, providing additional benefit to practices. In 2019, the OEN Advisory Board voted to fund a Team-based Care for Diabetes Management ECHO program. The Board selected this topic based on participant interest and state quality incentive priorities. The planned 12-session ECHO pilot program will include topics such as behavioral interventions, management of diabetes complications, medication management, and health-related social needs interventions.

Later that same year, the OHA Transformation Center asked ORPRN to submit a proposal to assist primary care practices in improving primary care diabetes care by using quality improvement training and PFs. Based on initial work for the Diabetes ECHO program, we coordinated topic areas and planned trainings in the proposal. We included regional quality improvement trainings for key office staff, tailored practice facilitation, and priority enrollment for clinicians and primary care practice staff to participate in the Team-based Care for Diabetes Management ECHO program. Coordinating these 2 projects will also allow us to study the outcomes of importance for both ECHO and practice transformation. ${ }^{1,26}$

\section{Financial Stability}

Currently, PBRNs struggle financially. ${ }^{1,13,14}$ Early sources of infrastructure support from Agency for Health care Research and Quality and occasionally Clinical and Translational Science Awards are now rare. ORPRN, like over $75 \%$ of PBRNs, is affiliated with an academic health center and, like many such PBRNs, currently receives no infrastructure support from its home institution. ${ }^{2}$ Excluding OEN funding, in 2019, ORPRN received its funding from federal grants (20\%), federal contracts $(12 \%)$, state of Oregon contracts (22\%) and other grants (primarily Patient-Centered Outcomes 
Research Institute and foundations, 47\%). Like all organizations dependent on grants and contracts, we alternate between lean periods when we must downsize staff and curtail activities and flush periods when we must ramp up staffing and resources to perform the needed work. Successful PBRNs strive to diversify their income streams to minimize such disruptions.

Nationally and globally, most ECHO programs are also funded through grants. ${ }^{27}$ As noted previously, we created the OEN with initial funding from 4 CCOs and 1 health plan partner. We believe $\mathrm{OEN}$ is the first ECHO program nationally to receive a significant amount of funding (30\% of operating budget) from nongrant sources. Partners commit to 2-year contracts, which provides predictable and sustainable funding to maintain programs and infrastructure support. Additional OEN funding comes from grants, contracts, and payments from organizations wanting to offer an ECHO program. As OEN programs continue to integrate with other ORPRN research and transformation activity, the addition of this predictable and flexible funding source for the overall ORPRN budget assists us in achieving more consistency in our budgeting. For example, during the early days of the COVID-19 pandemic, we quickly created and implemented a COVID-19 Response for Frontline Clinicians ECHO program. At the same time, we had to scale back and delay other ORPRN research projects. We used OEN funds to support the COVID-19 ECHO program and temporarily moved some ORPRN research staff to support in the COVID-19 ECHO programs. Because the OEN is part of ORPRN, we were able to both rapidly implement this important ECHO program and keep several additional ORPRN staff fully employed.

\section{Discussion}

Primary care PBRNs, like ORPRN, exist to improve the quality of primary care provided by their member practices, with an ultimate goal of improving the health of patients and communities. They do this through research and support of quality improvement and practice transformation. Project ECHO also exists to improve the quality of primary care provided by their participating practices, but ECHO's method is to support clinicians with case-based telementoring programs. ORPRN is certainly not the only PBRN to offer ECHO programs, ${ }^{28,29}$ but to our knowledge, we are the only PBRN to create an ECHO network within our PBRN that is partially funded by and coordinates with funders, health systems, and state agencies. We also believe we are 1 of a small number of organizations $^{30}$ that strives to coordinate its research, practice transformation, and ECHO programs.

Successful PBRNs regularly seek out the input of their members and other interested parties, including funders, state agencies, and health systems, in deciding which grants, applications, and proposals to pursue. ${ }^{31,32}$ Through ORPRN's advisory board of practicing physicians, ongoing practice facilitation visits with practices, and yearly membership convocations, ORPRN does well in understanding the needs of primary care practices. With the addition of the OEN, however, ORPRN now has a second advisory board that consists of CCOs (Medicaid payers), commercial and Medicare payers, and health systems. In addition, with OEN's robust program evaluation, participants regularly give input about their ongoing educational and practice support needs. As 1 organization, we share these important networking experiences across ORPRN's research, transformation, and ECHO staff. It is important that we offer both ECHO programs and research opportunities that align with state and national priorities and participant interest. We strive to develop programs with demonstrated interest rather than pushing topics on participants.

OEN's unique organizational structure of partner membership fees provides a funding stream independent of grants. ORPRN created the path to this outcome by engaging with new partners. Most PBRNs depend on grants for their support, but a diversification of funding is critical to long-term success. ${ }^{7,11,13}$ Gaglioti et al. ${ }^{7}$ wrote that PBRNs must be "intentional around our process of building relationships with stakeholders in the current and potential future funding environments to support the infrastructure of PBRNs." ORPRN built those relationships and diversified its research portfolio by pursuing and winning technical assistance contracts from the OHA. Our success with these state contracts came, in part, from our reputation with previous implementation research. ${ }^{22,26,33}$ These technical assistance contracts then furthered relationships that allowed ORPRN to competitively propose an ECHO network within our PBRN. Our strong connections with state agencies, state and 
federal lawmakers, and health care systems have aligned ORPRN with new partners who focus not only on clinical expertise but also on health systems, policy, and funding, which is a key strength for the future of our PBRN.

ORPRN, as a statewide PBRN in Oregon, has had opportunities that may not be available, and therefore might limit, the ability of other PBRNs to create a similar program to ours. Oregon has only 1 academic health center (OHSU), which has helped ORPRN's ability to work strategically with state agencies, such as the OHA. Oregon is a very rural state, with $35 \%$ of its population living in the rural or frontier counties that cover more than $75 \%$ of the state. ORPRN's practice facilitators, based around the state, have allowed our organization to work across these geographic barriers and become a key partner for supporting quality in rural Oregon. In addition, Oregon's investment in CCOs has greatly influenced how primary care is practiced in Oregon. ORPRN, along with the OEN, has actively worked to collaborate with CCOs and health systems to best support primary care transformation initiatives in the state.

It is not surprising that PBRNs may want to support, sponsor, and promote ECHO programs, ${ }^{28,29}$ as the overarching goals of both programs support primary care quality. By creating an infrastructure for ECHO programs within a primary care PBRN, however, we have found benefits for both PBRN research and transformation projects and ECHO programs. Although many ORPRN research and transformation projects do not use project $\mathrm{ECHO}$ at all, we have used the synergy to create quality projects and programs that build off the strengths of each component. We also benefit from improved recruitment and retention of practices and participants across our state, and OEN's unique membership fee funding structure has given ORPRN a more stable and diversified funding portfolio. We have found that integrating an ECHO network within our PBRN has helped us achieve the engagement and diversification recommended over the last decade by PBRN leaders. ${ }^{4,713,21,34}$

To see this article online, please go to: http://jabfm.org/content/ 33/5/789.full.

\section{References}

1. Davis MM, Keller S, DeVoe JE, Cohen DJ. Characteristics and lessons learned from practice- based research networks (PBRNs) in the United States. J Healthc Leadersh 2012;4:107-16.

2. Tierney WM, Oppenheimer CC, Hudson BL, et al. A national survey of primary care practicebased research networks. Ann Fam Med 2007;5:242-50.

3. Fagnan LJ, Morris C, Shipman SA, Holub J, King A, Angier H. Characterizing a practice-based research network: Oregon Rural Practice-Based Research Network (ORPRN) survey tools. J Am Board Fam Med 2007;20:204-19.

4. Hickner J, Green LA. Practice-based research networks (PBRNs) in the United States: growing and still going after all these years. J Am Board Fam Med 2015;28:541-5.

5. Green LA, Hickner J. A short history of primary care practice-based research networks: from concept to essential research laboratories. J Am Board Fam Med 2006;19:1-10.

6. Fiscella K. Improving the health of patients and communities: evolving practice-based research (PBR) and collaborations. J Am Board Fam Med 2017;30:562-6.

7. Gaglioti AH, Werner JJ, Rust G, Fagnan LJ, Neale AV. Practice-based research networks (PBRNs) bridging the gaps between communities, funders, and policymakers. J Am Board Fam Med 2016; 29:630-5.

8. Mold JW, Peterson KA. Primary care practicebased research networks: working at the interface between research and quality improvement. Ann Fam Med 2005;3:S12-S20.

9. Westfall JM, Fagnan LJ, Handley $M$, et al. Practice-based research is community engagement. J Am Board Fam Med 2009;22:423-7.

10. Westfall JM, Mold J, Fagnan L. Practice-based research-"Blue Highways" on the NIH roadmap. JAMA 2007;297:403-6.

11. Binienda J, Neale AV, Wallace LS. Future directions for practice-based research networks (PBRNs): a CERA survey. J Am Board Fam Med 2018;31:917-23.

12. Green LA, White LL, Barry HC, Nease DE, Jr., Hudson BL. Infrastructure requirements for practice-based research networks. Ann Fam Med 2005;3:S5-S11.

13. Elder NC. Practice-based research today: a changing primary care landscape requires changes in practice-based research network (PBRN) research. J Am Board Fam Med 2019;32:647-50.

14. Rhyne RL, Fagnan LJ. Practice-based research network (PBRN) engagement: $20+$ years and counting. J Am Board Fam Med 2018;31:833-9.

15. Arora S, Geppert CM, Kalishman S, et al. Academic health center management of chronic diseases through knowledge networks: Project ECHO. Acad Med 2007;82:154-60. 
16. Arora S, Kalishman S, Thornton K, et al. Project ECHO (Project Extension for Community Healthcare Outcomes): a national and global model for continuing professional development. J Contin Educ Health Prof 2016;36:S48-S9.

17. Serhal E, Arena A, Sockalingam S, Mohri L, Crawford A. Adapting the consolidated framework for implementation research to create organizational readiness and implementation tools for project ECHO. J Contin Educ Health Prof 2018; 38:145-51.

18. Langston C. Health Affairs blog. Project Hope. Available from: https://www.preventcancer.org/wpcontent/uploads/2018/06/Project_ECHO_Enthusiasm_ Overtakes_Evidence.pdf. Published. 2017.

19. McConnell KJ. Oregon's Medicaid coordinated care organizations. JAMA 2016;315:869-70.

20. Stock R, Goldberg B. Health reform policy to practice: Oregon's path to a sustainable health system: a study in innovation. San Diego (CA): Elsevier; 2017.

21. Calmbach WL, Ryan JG, Baldwin LM, Knox L. Practice-based research networks (PBRNs): meeting the challenges of the future. J Am Board Fam Med 2012;25:572-6.

22. Parchman ML, Anderson ML, Dorr DA, et al. A randomized trial of external practice support to improve cardiovascular risk factors in primary care. Ann Fam Med 2019;17:S40-S9.

23. Parchman ML, Penfold RB, Ike B, et al. Teambased clinic redesign of opioid medication management in primary care: effect on opioid prescribing. Ann Fam Med 2019;17:319-25.

24. Von Korff M, Saunders K, Dublin S, et al. Impact of chronic opioid therapy risk reduction initiatives on opioid overdose. J Pain 2019;20:108-17.

25. Parchman ML, Von Korff M, Baldwin LM, et al. Primary care clinic re-design for prescription opioid management. J Am Board Fam Med 2017;30:44-51.
26. Parchman ML, Hsu C, Fagnan L, van Borkulo N, Tuzzio L. Building a learning health care organization: external facilitation tailors support to the learning capacity of primary care settings. J Patient Cent Res Rev 2017;4:187.

27. US Department of Health and Human Services. Current state of technology-enabled collaborative learning and capacity building models. Available from: https://aspe.hhs.gov/pdf-report/report-congresscurrent-state-technology-enabled-collaborativelearning-and-capacity-building-models. Published 2019.

28. West Virginia Clinical and Translational Science Institute. Active WVPBRN projects. Available from: http://wvctsi.org/programs/community-engagementoutreach/practice-based-research-network/researchprojects/active-wvpbrn-projects/. Published 2019.

29. LANet. Project ECHO L.A. Available from: http:// www.projectechola.org/. Published 2019.

30. Weitzman Institute. Weitzman ECHO. Available from: https://www.weitzmaninstitute.org/projectecho. Published 2019.

31. Fisher M, Brewer SE, Fernald DH, et al. Process for setting research priorities: a case study from the state networks of Colorado Ambulatory Practices and Partners (SNOCAP) Consortium. J Am Board Fam Med 2019;32:655-62.

32. Gaglioti AH, Walston D, Vasquez Guzman CE, et al. A practical approach to establishing a practice-based research network stakeholder engagement infrastructure. J Am Board Fam Med 2019; 32:695-704.

33. Parchman ML, Anderson ML, Coleman K, Michaels LA, et al. Assessing quality improvement capacity in primary care practices. BMC Fam Pract 2019;20:103.

34. Nease DE., Jr. Evidence, engagement, and technology: themes of and the state of primary care practice-based network research. J Am Board Fam Med 2016;29:521-4. 